Article

\title{
Is Housing Growth Ever Inclusive Growth? Evidence from Three Decades of Housing Development in England and Wales, 1981-2011
}

\author{
Rebecca Tunstall \\ Centre for Housing Policy, University of York, Heslington, YO10 5DD, UK; E-Mail: becky.tunstall@york.ac.uk
}

Submitted: 15 January 2020 | Accepted: 28 April 2020 | Published: 31 July 2020

\begin{abstract}
There is global concern about who gains from economic growth, including housing development, and global interest in making growth more inclusive. This article creates a new definition of 'housing growth,' growth in median space per person. It says that this housing growth is 'inclusive' if the worst-off make some gains, and 'just' if inequality does not increase. It applies these terms to data for 1981-2011 on rooms per person for England and Wales, the bulk of the UK, a nation with high income inequality but lower housing inequality. At national level, median housing space increased but the worst-off gained nothing, and inequality rose, so growth was neither inclusive nor just. Sub-national evidence shows that housing growth benefitted the worst-off in most areas, but they generally made very modest gains, and growth without increasing inequality was very rare. There was housing growth in all 10 regions except London, it was inclusive in 6 regions, but not just in any region. $97 \%$ of local authorities experienced housing growth, and it was inclusive in $72 \%$, but the average gain for the worst-off was just 0.2 rooms/person over thirty years. Only $3 \%$ of local authorities achieved both inclusive and just growth. This suggests that in the UK and similar nations, local initiatives will be insufficient to achieve growth with significant gains for the worst-off, and that substantial change to the national system of housing development and allocation is needed. There may be a policy choice between benefitting the worst-off and reducing inequality. There is potential for further and comparative research.
\end{abstract}

\section{Keywords}

housing development; housing space; inclusive growth; inequality

\section{Issue}

This article is part of the issue "Home, Housing and Communities: Foundations for Inclusive Society" edited by Isobel Anderson (University of Stirling, UK), Vikki McCall (University of Stirling, UK) and Joe Finnerty (University College Cork, Ireland).

(C) 2020 by the author; licensee Cogitatio (Lisbon, Portugal). This article is licensed under a Creative Commons Attribution 4.0 International License (CC BY).

\section{Introduction}

Many high-income countries with relatively good housing conditions face growing problems of housing affordability, overcrowding and homelessness and continued poor conditions for a minority, despite high rates of housing development (Stephens, Perry, Wilcox, Williams, \& Young, 2019). These parallel the persistence of wider problems of poverty, unemployment and inequality despite economic growth in countries across the world (Benner \& Pastor, 2012; Kohil, Moon, \& Sorensen, 2003; Piketty, 2014).

Many people and organisations believe that housing problems are principally caused by insufficient sup- ply and that increased supply is the solution. This article explores the extent to which the nature of supply and distribution are significant to overall outcomes. In parallel with the ideas of 'inclusive' growth and 'just' growth, used to characterise economic growth in general, it sets out definitions of 'inclusive' housing growth and the more challenging 'just' housing growth. It applies these to data on housing space per person in England and Wales for 1981-2011. England and Wales form the main part of the UK, a nation with high income inequality, but low housing inequality compared to EU nations.

The article demonstrates that inclusivity and justness of growth in housing space can be defined and measured, although results are sensitive to the exact defini- 
tions and measures used. It shows that for England and Wales 1981-2011, 'inclusive' growth, where the worstoff gained at least some space in absolute terms, was widespread. However, they generally made very modest gains compared to other groups. 'Just' housing growth, with no increase in housing space inequality, was extremely rare, even at the local level, despite considerable local variations in demographics and housing development. However, the England and Wales housing system was able to benefit the worst-off and avoid increases in inequality in decades before 1981. Overall, this evidence suggests that there is considerable potential for making housing supply more inclusive, as a complement, supplement or even alternative to increased supply, but that systematic, national level change would be required to achieve it. It seems likely that similar results might be found for similar nations, for periods when housing development and distribution were dominated by the market, or there was high income inequality.

\section{Inclusive Growth}

The concept of 'inclusive' economic growth developed after concern about whether economic growth, both in high and low income countries, had provided sufficient employment, income or other benefits to the less well-off (Commission on Growth and Development, 2008; OECD, 2008). In the past, many economic theorists argued that at least some benefit from economic growth would trickle down to less advantaged parts of the population, but a substantial body of evidence from many countries demonstrates that this is often not the case. Five decades of economic growth in the UK have coexisted with increasing income inequality and relative, particularly since the late 1970 s (Hills et al., 2010; Lupton, Burchardt, Hills, Stewart, \& Vizard, 2016). While the UK has high rates of poverty compared to EU states, similar patterns are seen round the world (OECD, 2018; Piketty, 2014). Traditionally, economists have assumed that there is a trade-off between equity and efficiency, but some have argued that very high levels of inequality themselves create a limit to growth (Benner \& Pastor, 2012; Kohil et al., 2003). In response, institutions including the World Bank, the OECD and the European Commission have adopted the idea of 'inclusive growth' as an overarching goal for economic policy (Commission on Growth and Development, 2008; European Commission, 2010; OECD, 2008), and the UN launched a 'sustainable and equitable cities' campaign in 2016 (Phang, 2019).

The World Bank has defined 'inclusive growth' as growth that "allows people to contribute to and benefit from economic growth" (lanchovichina \& Lundstrom, 2009). This does not require that contributions and benefits be equal or even fair. In contrast, the OECD definition is growth that, "creates opportunity for all segments of the population and distributes the dividends of increased prosperity, both in monetary and non-monetary terms, fairly across society" (OECD, 2018). This includes but does not define 'fairness.' The UK's Royal Society of Arts and Manufactures adopted a maximalist definition for use in the UK, so that inclusive growth was "enabling as many people as possible to contribute to and benefit from growth" (Inclusive Growth Commission, 2017 , p. 6). The term 'just growth' is a near-synonym, but definitions and measures of just growth tend to refer explicitly to inequality in income (Benner \& Pastor, 2012; Chapple, 2018; Kohil et al., 2003). Evidence shows that inclusive growth, however defined and measured, is difficult to achieve. For example, of the BRICS counties, which all achieved dramatic growth over the 2000s and 2010s, only Brazil avoided substantial increases in income inequality (Vandemoortele et al., 2013). Numerous reports have tried to describe the policies and practices that might encourage more inclusive growth (Benner \& Pastor, 2012; Chapple, 2018; Lee, 2019).

Alongside interest in inclusive growth as a policy goal, there is also growing interest in non-growth, on environmental grounds. The value of growth in GDP, particularly as currently measured, has been challenged (Bleys, 2012). In some areas, periods of low or no growth have been associated with stable or even reducing income inequality, for example after the 2008 financial crisis in the UK (ONS, 2019).

\section{Housing Growth, Inclusivity and Justness}

From the 2000s, independent commentators agreed that the UK housing system had serious structural problems, including persistent undersupply of new homes (Hall, 2011; Stephens et al., 2019; Whitehead \& Williams, 2011). For example, household growth exceeded home building by 500,000 in 2008-2015 (Cole et al., 2017). Since the 2000s, there have been all the signs of pent-up demand: high house prices, widespread difficulties with affordability, declining home ownership and marked increases in overcrowding, concealed households, households in temporary accommodation and homelessness (Fitzpatrick et al., 2019; Stephens et al., 2019). Many of these problems are shared by housing systems in other countries (CECODHAS, 2019; Council of European Development Bank, 2017; Scanlon, Arrigoitia Fernandez, \& Whitehead, 2015).

Is insufficient supply of new homes the main cause of housing problems in the UK and elsewhere? Would increasing supply help solve the problems? A 2017 UK government housing white paper said that it was "very simple": Undersupply was the problem and more supply was the solution (Department for Communities and Local Government, 2017, p. 9). This argument was repeated in the winning 2017 and 2019 General Election manifestos (Conservative Party, 2019). Similarly, House of Commons researchers (required to be politically neutral) stated that "homelessness is the most visible manifestation of the long-term failure of successive Governments to build enough" (Wilson \& Barton, 2019, p. 10). However, recent 
decades have seen a substantial increase in the supply of housing space. The England and Wales census shows that over 1981-2011, the number of rooms (including living rooms, bedrooms and kitchens big enough to eat in) grew by $39 \%$. This ran ahead of growth in population (15\%) and household numbers (32\%).

Some commentators have suggested that insufficient supply may not fully explain problems, and that the distribution of housing also needs to be examined (Dorling, 2014). New housing may have no effect on those on low incomes, who will not be able to afford to live in most, if any, new housing, and it has been suggested that there might even be a trade-off between increasing housing supply and reducing housing inequalities (Robinson, O'Sullivan, \& Le Grand, 1985). Housebuilding can be very inefficient at helping the worst-off. It took from 1911-1991 for the worst-housed in England and Wales in terms of housing space per person (people at the 10th percentile of the distribution) to get to 1.0 room per person, which had the national median in 1911 (Tunstall, 2015). There is evidence of increasing inequality in housing space, for example, in countries including the USA (Landis, Elmer, \& Zook, 2002) and China (Feng, 2008; Tan, Wang, \& Chen, 2016) and increasing inequality in housing wealth (Arundel, 2017; Piketty, 2014; Robinson et al., 1985).

This article focuses on housing space as a key dimension of housing quantity and quality. Housing space is only one way of conceptualising and measuring the consumption of housing and housing inequality, but it is a valid and important one. A century of studies has demonstrated correlations between 'overcrowding' and negative outcomes; from 'immorality' to poor health and worse educational achievement (Marmot Review Team, 2010; Marsh, Gordon, Heslop, \& Pantazis, 2000). Overcrowding, or absolute low consumption of housing has been a key preoccupation of housing policy in the UK and elsewhere since its origins (General Register Office, 1904; Goodchild \& Furbey, 1986), and it is now addressed in one of the UN's worldwide Sustainable Development Goals. In high income countries like the UK, decades of rising incomes and public investment have meant big rises in average space per person, and big falls in the proportions of residents below absolute minima (Tunstall, 2015). Similar patterns are seen in medium and low income countries. However, even in rich countries a new 'politics of housing space' has emerged as part of debates over housing finance and affordability (Carr, 2016). For example, should there be subsidy for people to have space above legal minimums but not above societal norms? In the UK this issue has taken the form of debates over the so-called 'bedroom tax' of 2012, which reduced housing allowances for low-income social renters with more space than the minimum (Carr, 2016; Gibbons, Sanchez-Vidal, \& Silva, 2018).

This article describes 'housing growth' as an increase in median housing space per person over time, just as GDP growth is sometimes expressed per head of pop- ulation. Although this argument cannot be explored in depth, it should be noted that just as the goal of GDP growth has been questioned, some observers might see housing 'non-growth' as preferable to housing growth on environmental grounds (building additional housing space will almost always mean additional net production of carbon dioxide, even where the homes themselves meet 'zero carbon' standards).

This article uses two measurable definitions of the quality of housing growth:

1. 'Inclusive' housing growth occurs when there is both 'housing growth' (an increase in the median housing space per person), and the worst-off (those at the 10th percentile in terms of housing space per person) make absolute gains.

2. 'Just' housing growth occurs when there is both 'housing growth,' and no growth in housing space inequality between people (measured by the ratio of housing space of those at the 90th and the 10th percentile).

This article aims to demonstrate the application of the concepts and measures of 'inclusive' and 'just' growth to housing, focusing on housing space. It also aims to answer the following questions:

1. Which parts of England and Wales achieved 'housing growth' between 1981-2011, in terms of median housing space per person?

2. Which, if any, achieved 'inclusive' or 'just' housing growth over the same period?

3. What are the characteristics of regions and/or local authorities that achieved inclusive growth or just growth?

4. What are the implications for other nations and areas, and for those who wish to promote more inclusive or just housing growth?

What circumstances might promote housing growth, and inclusive and just housing growth? Firstly, logically, high growth in the quantity of housing and low population growth will necessarily result in a high growth in mean space per person, and should be expected to produce high growth in median space per person, or high 'housing growth,' as defined here. However, depending on distribution, the mean could grow with little or no change in the median. Low growth in the quantity of space and high population growth will necessarily result in low or no growth in mean space per person, and could be expected to produce low growth in median space per person (high housing growth), although again there may not be a direct relationship. Secondly, logically, growth in space per person (whether mean or median) and low population growth could both be expected to give more opportunities for 'inclusive' growth. The worst-off could gain in absolute terms, and the best-off could also gain. Similarly, for 'just' growth, the worst-off could gain in 
relative terms while the best-off could still gain in absolute terms. Overall, this suggests we might expect to find more cases of inclusive and just growth in areas with high rates of housing development, low population growth, or growth in mean or median space per person. However, again, results will depend on distribution.

As understanding of the inclusivity of housing growth develops, more formal hypotheses to explain variations will develop. However, tentatively, it might be expected that larger population, more urban and more deprived areas might have a stronger political or systemic orientation towards improving conditions for the worst-off. On the other hand, they might struggle more to do so, or to provide housing growth. In addition, there is evidence that large cities and have higher income inequality that other parts of their nations (Phang, 2019; Trust for London, 2017), and this could apply to housing space.

\section{Data and Methods}

The UK (comprised of England, Wales, Scotland and Northern Ireland) was selected as an example of a highincome, OECD and former EU-28 member country. It has similar amounts of housing space per person to comparable countries: In 2008 the average English home provided $37 \mathrm{~m}^{2}$ internal floorspace per person, compared to $37 \mathrm{~m}^{2}$ in France, $35 \mathrm{~m}^{2}$ in Germany and $61 \mathrm{~m}^{2}$ in the USA (Ministry of Housing Communities and Local Government [MHCLG], 2018). It has relatively high income inequality (ONS, 2019; Piketty, 2014). However it appears to have relatively low housing inequality, including in terms of housing space, as the gaps between the housing conditions of poor people and the national average are smaller in the UK than in many EU countries (Bradshaw, Chzhen, \& Stephens, 2008; Eurostat, 2020).

Assessing trends in the distribution of housing space alongside trends in housing growth and at sub-national level requires longitudinal and disaggregatable data. While most countries in Europe gather survey data on internal floorspace (Eurostat, 2020), and the Survey of English Housing has recently started to assess floorspace (MHCLG, 2018), in the UK the only suitable long-run and local data on housing space is on the number of rooms, from the census. Although the size of rooms in England appeared to reduce slightly in the 1980s and 1990s (MHCLG, 2018), the number of rooms provides some proxy for overall space, and also suggests how a home can accommodate different uses and users. However, census data have some drawbacks: Results are only comparable for England and Wales, not the whole UK, and the latest datapoint was 2011 so the census cannot be used to assess effects of recent changes such as the 'bedroom tax.'

Numerous measures have been developed to describe the characteristics of the overall distribution of income across societies, including proportions of people below absolute or relative minima, such as the definition of poverty as income below $60 \%$ of the median, ratios between different parts of the distribution, and the Gini coefficient which describes the overall shape of the distribution (Atkinson, 1970; Hills et al., 2010). No one measure of inequality is entirely comprehensive or 'neutral' (Atkinson, 1970). However, most studies of housing inequality have been restricted to categorical measures, counting people without certain amenities or below minima (de Wilde \& de Decker, 2016; Hills et al., 2010; Murie, 1983). Measuring inequality in more sophisticated ways, as required by the definitions of 'inclusive' and 'just' growth above, demands continuous concepts and data (Dorling et al., 2005; Robinson et al., 1985).

The analysis in this article creates quasi-continuous data on the number of private households with different combinations of numbers of rooms and numbers of people, from the census. Data on the rooms and people in individual households were extracted from online sources at Casweb (http://casweb.mimas.ac.uk) and Nomisweb (www.nomisweb.co.uk). 'Rooms' include bedrooms, living rooms and larger kitchens (big enough to eat in). The population was divided up into groups according to the rooms per person they had, and ordered from low to high rooms per person, creating quasi-continuous data Because the data includes only people living in private households, excludes second homes, and assumes that rooms occupied by a household are shared equally between residents (not taking account of potential differences in space needs between people), it will generally tend to underestimate inequality.

The article reports the position of the 'worst-off' focussing on those at the 10th percentile of the overall distribution. It reports housing space inequality using the 90:10 ratio, the ratio between the housing space per person of those at the 10th and 90th percentiles. This is one of the mostly widely used measures in the study of income and other social inequalities, is simple to understand, and is more sensitive to the lower end of the distribution than the Gini coefficient (Atkinson, 1970; Hills et al., 2010). Other similar ratios such as 90:50 and 50:10) are also widely used.

Understanding how to develop intentional strategies for inclusive growth "is an important area for comparative research" (Chapple, 2018, p. 793). Comparing local areas allows us to explore the role of local contexts and policies in growth and its distribution (Benner \& Pastor, 2012). This article reports data for the 9 regions of England and for Wales, which correspond to NUTS 1 regions used by Eurostat. It also reports data for the 348 local authorities in England and Wales. They are the key planning agencies in the UK, responsible for influencing and approving housing development plans of housebuilders and non-profit organisations. In 2011 they had average populations of just under 200,000 , with a range from 2,000 to $1,110,000$ (there were boundary changes over 1981-2011 but data shown are for boundaries as they were in 2015). 


\section{Housing Growth and Inclusivity at the National Level in England and Wales over the Twentieth Century}

Over the twentieth century, numbers of people, households and rooms in England and grew in every decade. In every decade, the number of rooms available increased faster than the number of people. However, the most recent period, 1981-2011, stands out for its declining rate of growth in new housing space combined with rising rate of population growth (Figure 1).

Mean space per person grew in every decade as the rate of growth in rooms ran ahead of growth in population. However, median housing space per person grew and there was 'housing growth' in only six decades. In the other four decades (1911-1921, 1921-1931, 1961-1971 and 1981-1991), housing space per person was unchanged, so there was no 'housing growth.'

Housing growth was both 'just' and 'inclusive' in 1931-1951 and 1951-1961. It was 'inclusive' but not 'just' in 1971-1981, as the worst-off gained but inequalities do not reduce. It was 'just' but not 'inclusive' in 1991-2001, as inequalities reduced but the worst-off did not gain. Periods with no growth could also be inclusive and just, and this was the case over 1961-1971 and 1981-1991. In 1911-1921 and 1921-1931, there was another combination: non-inclusive but just non-growth, where the worst-off lost out, the median reduced and inequalities reduced.

This article focusses on the most recent period, on the grounds that the most recent system is of most relevance to today.

\section{Which Parts of England and Wales Achieved Housing Growth between 1981-2011?}

\subsection{England and Wales}

Over the whole three decades 1981-2011, England and Wales as a whole experienced a $39 \%$ increase in the number of rooms (including living rooms, bedrooms and kitchens big enough to eat in). The number of households increased by $32 \%$, but the population grew by just $15 \%$. The mean people per household reduced, and the mean rooms per household increased. The mean rooms per person increased, and the median increased from 1.5 to $2.0 \mathrm{r} / \mathrm{p}$ (rooms per person), amounting to a $33 \%$ increase over thirty years. This took the median couple household, for example, from three rooms to four (Figure 2).

\subsection{Regions}

In 1981, median space was $1.5 \mathrm{r} / \mathrm{p}$ in each of the ten regions of England and Wales, except for the South West, where it was slightly higher at $1.7 \mathrm{r} / \mathrm{p}$.

Over 1981-2011, there were strong regional variations between regions in population change, and in the North East and North West, population actually fell (although it started to rise again in these regions at the end of the period). The number of households and rooms grew in every region, and there was less variation in rates of change between regions than for population change (Figure 3). The difference between the rate of growth in numbers of people and numbers of rooms accounts

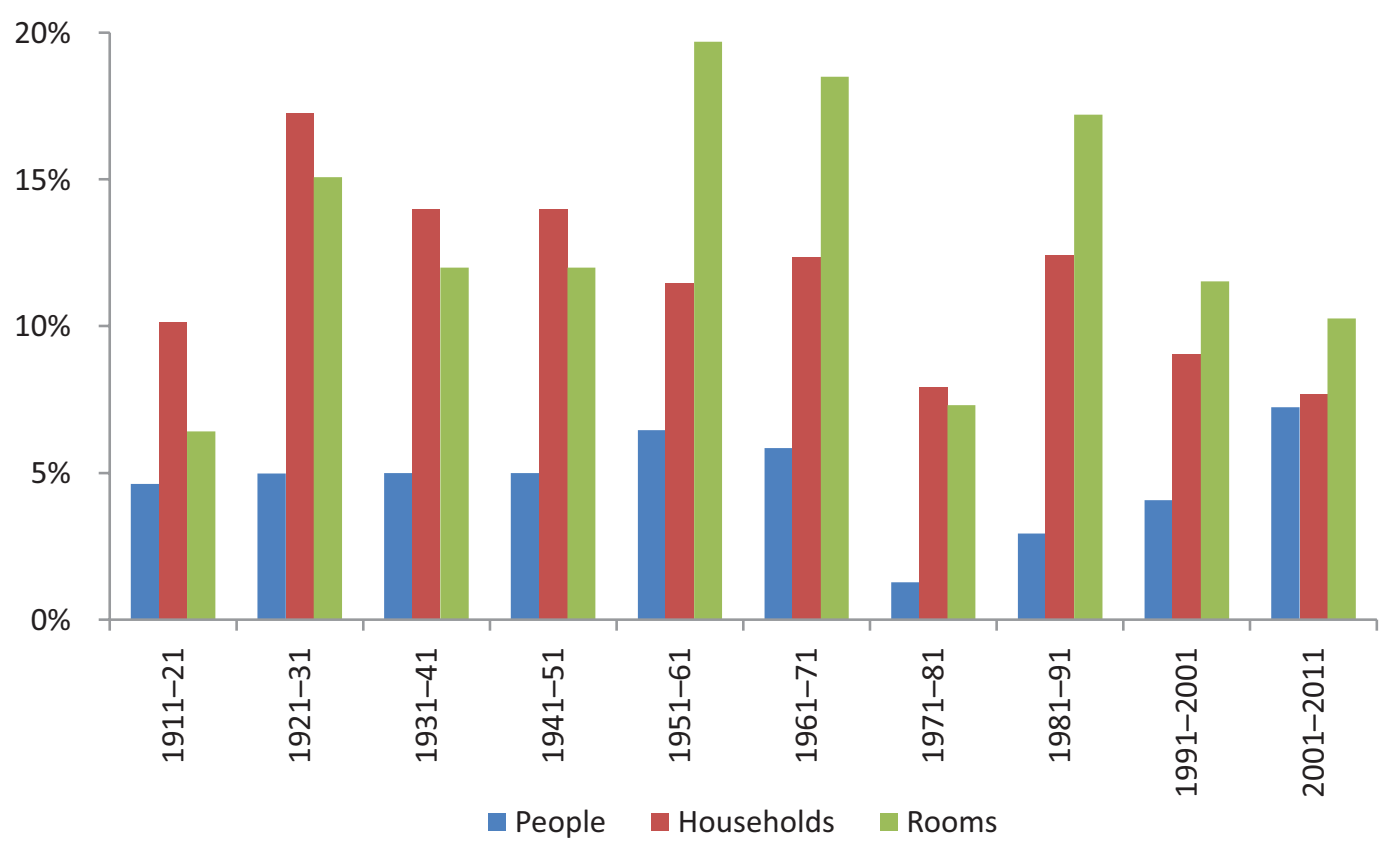

Figure 1. Rate of growth in number of people, households and rooms, England and Wales, 1911-2011. Compiled by the author based on data from Casweb for 1981 and Nomisweb for 2011. There was no census in 1941 due to WWII, so data for 1931-1941 and 1941-1951 are based on averaging data for 1931-1951. 


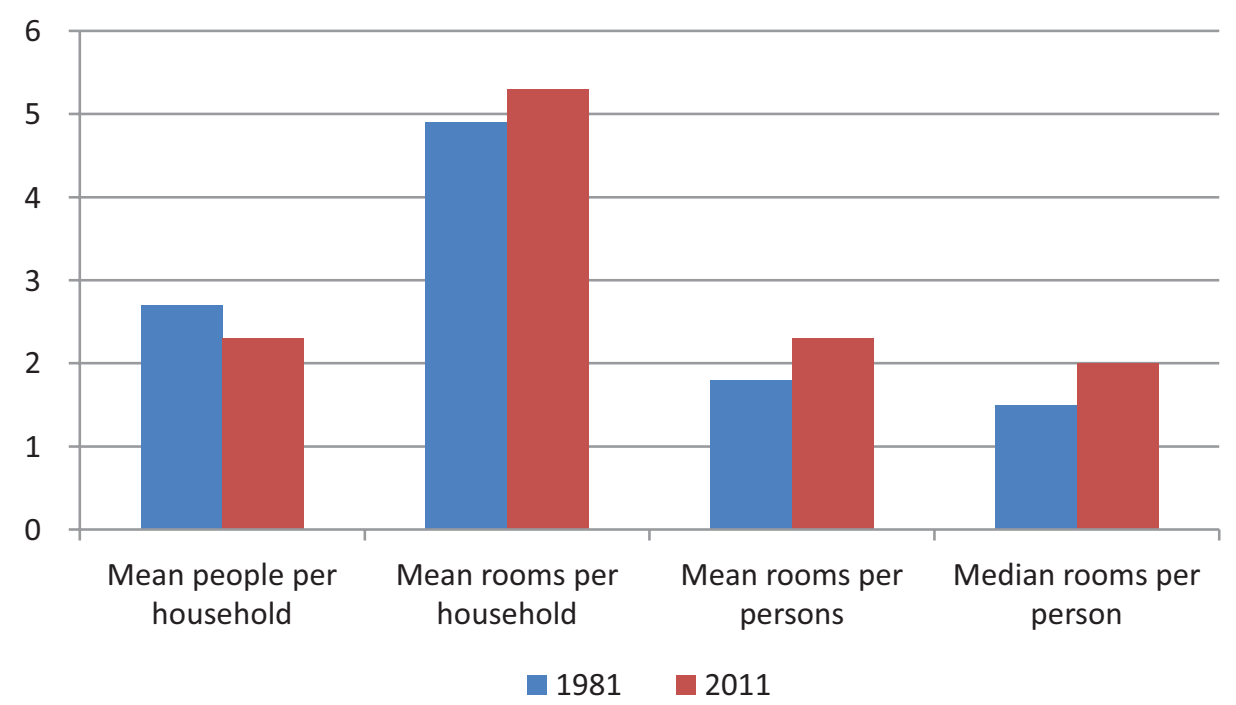

Figure 2. People, households, housing space and housing growth in England and Wales, 1981-2011. Compiled by the author based on data from Casweb for 1981 and Nomisweb for 2011.

for the growth in mean rooms per person (without taking account of actual distribution). London stands out for the small difference between the growth in rooms and growth in population it had.

The median housing space per person reflects the actual distribution of housing space between households and people. Over 1981-2011, the median increased, meaning there was housing growth, in every region but one, London. In most regions median housing space increased from $1.5 \mathrm{r} / \mathrm{p}$ to $2.0 \mathrm{r} / \mathrm{p}$ (or by $33 \%$ ). The South West which already had higher median space in 1981 than other areas, had a smaller increase, from 1.7 to 2.0 (20\%). Space per person in London was unchanged
1981-2011 at $1.5 \mathrm{r} / \mathrm{p}$, which made it the worst-housed region in 2011 in terms of housing space.

\subsection{Local Authorities}

In 1981, median space per person ranged from $1.3 \mathrm{r} / \mathrm{p}$ to $1.8 \mathrm{r} / \mathrm{p}$ between the 348 local authorities of England and Wales. This amounts to the difference between the relatively-crowded three people in four rooms, and the more generous four people in seven rooms. The local authorities with the lowest median space per person included eight of the 33 in London, all at $1.3 \mathrm{r} / \mathrm{p}$. The local authorities with the highest median space per person

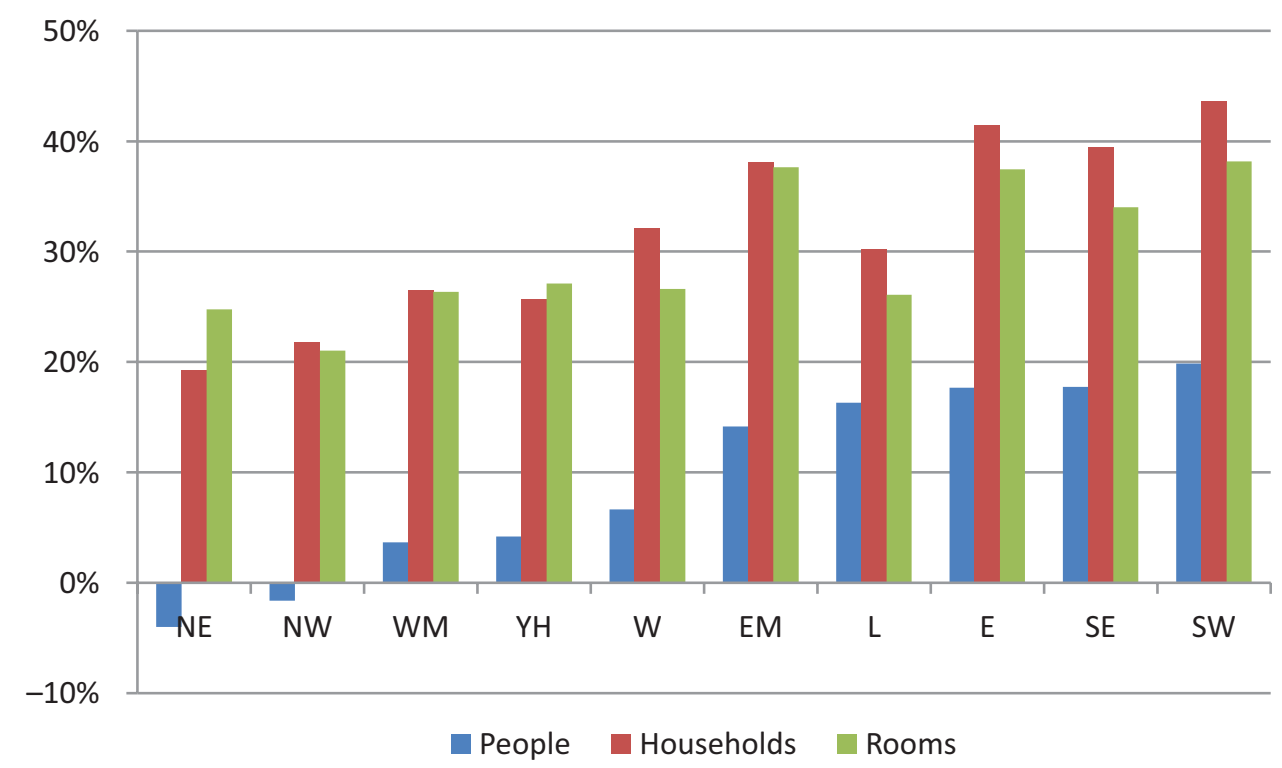

Figure 3. Rates of growth in numbers of people, households and rooms, regions, 1981-2011. Compiled by the author based on data from Casweb for 1981 and Nomisweb for 2011. The initials identify regions: West Midlands (WM); Yorkshire and Humberside (YH); Wales (W); East Midlands (EM); London (L). The remainder of initials refer to regions named after points of the compass. 
were mostly small and rural, for example, Ceredigion in Wales at $1.8 \mathrm{r} / \mathrm{p}$.

Over the thirty years 1981-2011, 339 (97\% of the total) local authorities experienced housing growth in median housing space per person. The biggest absolute increases were in rural and relatively advantaged areas which already had higher medians in 1981, like Cotswold in the South East (1.8 additional r/p). They were also urban and relatively deprived areas, which had had low medians in 1981, like Knowsley in the North West $(0.8$ additional $\mathrm{r} / \mathrm{p}$ ). In two areas in London, Newham and Waltham Forest, already low median space per person in 1981 reduced further by 2011. In 17 more, including 11 in London and four in the South East, there was no change or imperceptible growth of less than $0.1 \mathrm{r} / \mathrm{p}$.

Overall, across all local authorities, there was a small negative correlation between population growth and housing growth. This supports the idea that it might be more difficult for local housing systems to maintain housing growth when there is faster population growth. However, there was almost no relationship between housing growth and two other key characteristics of the local authorities: size in terms of absolute population in 1981 and deprivation (MHCLG, 2019).

\section{Which Parts of England and Wales Achieved 'Inclusive' and 'Just' Housing Growth 1981-2011?}

\subsection{England and Wales}

Across England and Wales, housing space for those at the worst-housed 10th percentile did not change 1981-2011. They had $1.0 \mathrm{r} / \mathrm{p}$ in 1981 and $1.0 \mathrm{r} / \mathrm{p}$ in 2011, thirty years later. Housing space inequality increased. In 1981, those at the 90th percentile had three times as much space per person as those at the 10th, but by 2011 they had four times as much space (an increase in the 90:10 ratio from 3.0 to 4.0 ). Thus, while there was housing growth at national level over the thirty years, it was neither inclusive nor just (Figure 4).

\subsection{Regions}

Figure 5 shows mean and median space per person by region. It confirms the differences between these measures, which reflect unequal distribution. It also shows which regions achieved housing growth and whether it was 'inclusive' or 'just.' Six regions (the North East, East Midlands, Wales, South West, North West and East) achieved inclusive but non-just growth. Three regions (the South East, Yorkshire and Humberside, and West Midlands) achieved non-inclusive, non-just growth. London had a third combination: non-inclusive, non-just non-growth (Figure 5).

Regarding inclusivity, in 1981, the worst-housed in every region had $1.0 \mathrm{r} / \mathrm{p}$. Over 1981-2011, the worst-off made small absolute gains of $0.2 \mathrm{r} / \mathrm{p}$ in 6 regions (the North East, the North West, the East Midlands, the East, the South West and Wales. In three regions (the South East, Yorkshire and Humberside, and the West Midlands), there was no change. In London, the worst-off actually lost in absolute terms, going from 1.0 to $0.8 \mathrm{r} / \mathrm{p}$.

Regarding justice, in 1981, the 90:10 ratio was 3.0, the same as the national ratio, for every region. Over 1981-2001, the ratio increased in every region, by between $11 \%$ and $33 \%$, so no region had 'just' change.

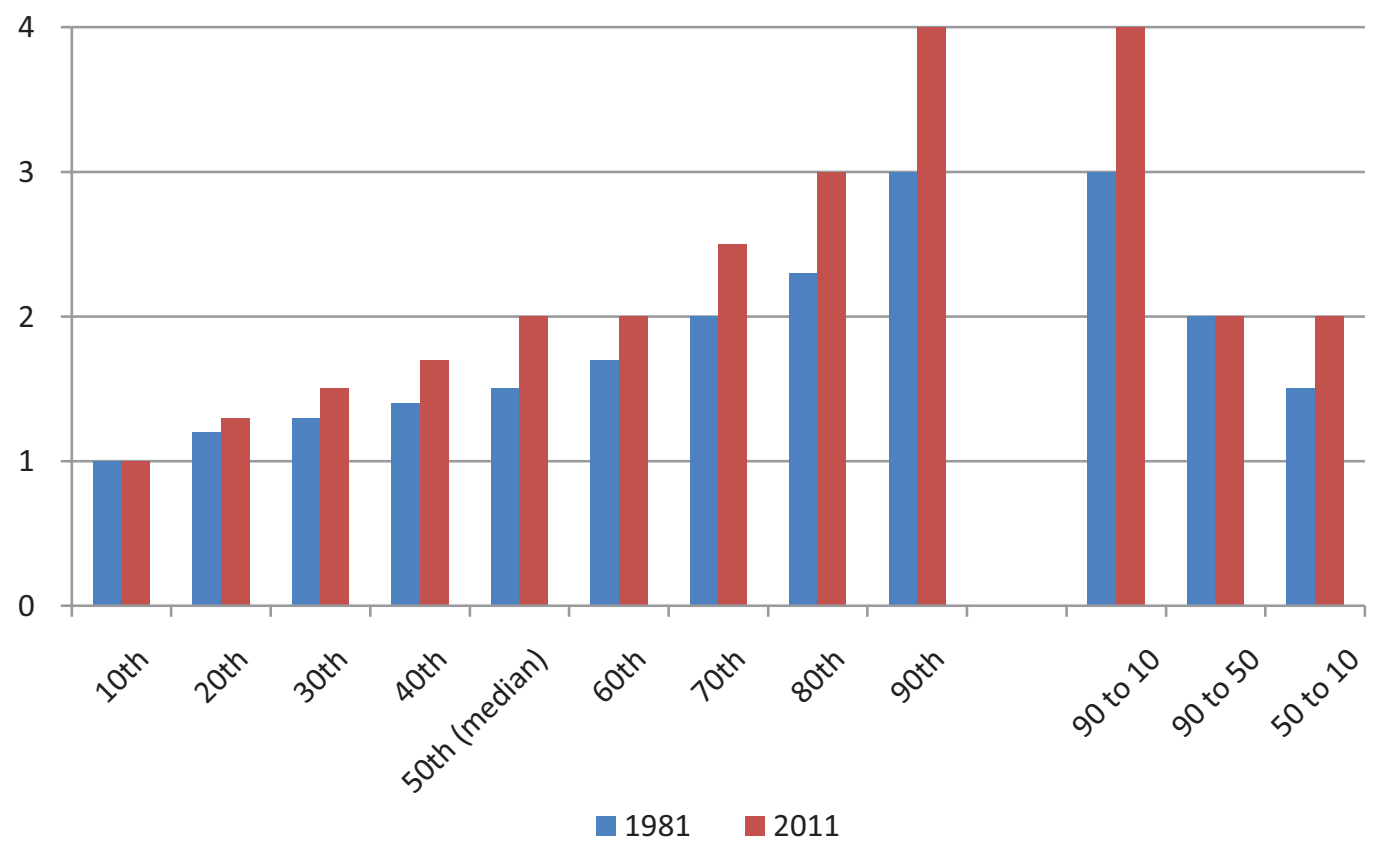

Figure 4. Housing space in rooms per person in England and Wales by percentile and ratios between percentiles, 1981 and 2011. Compiled by the author based on data from Casweb for 1981 and Nomisweb for 2011. 


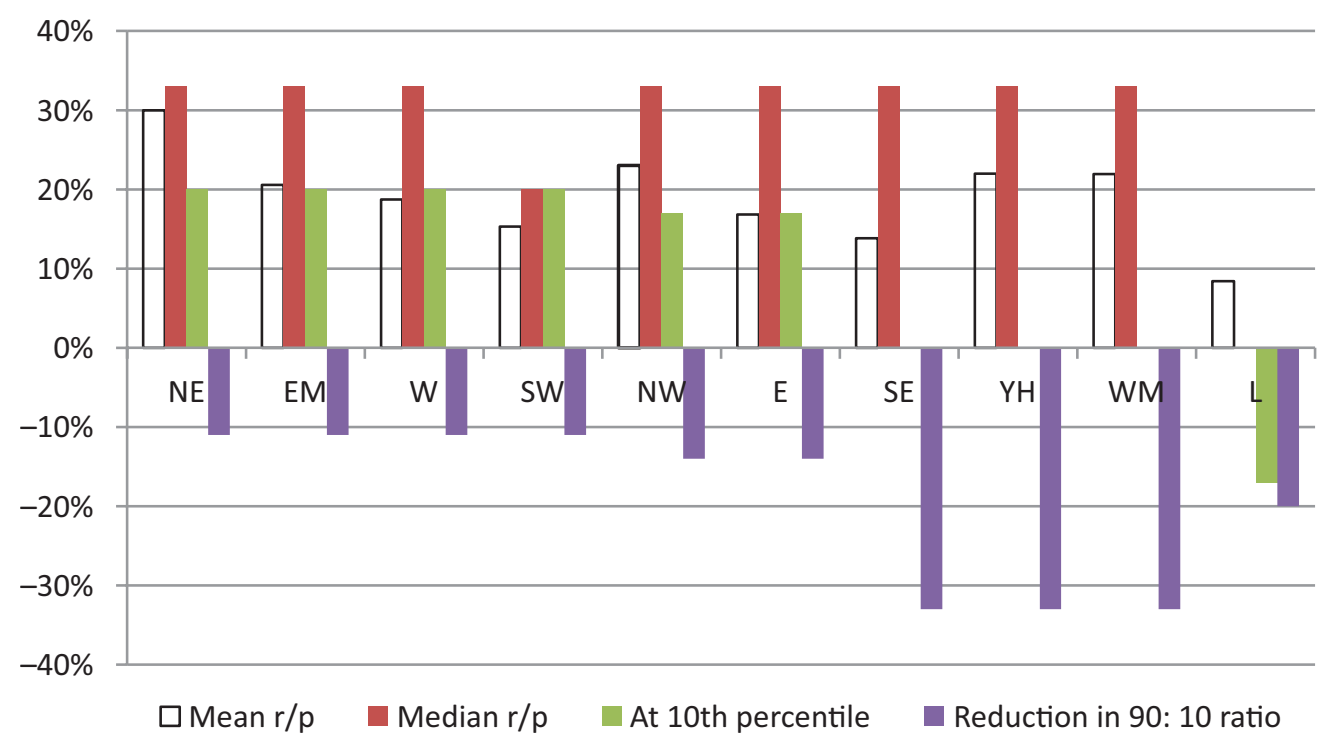

Figure 5. Rates of growth in mean rooms per person, median rooms per person (housing growth), rooms per person at the 10th percentile (inclusivity) and reduction in 90:10 ratio (justness), regions of England and Wales, 1981-2011. Compiled by the author based on data from Casweb for 1981 and Nomisweb for 2011.

London experienced a typical increase in inequality, but in 2011 remained among the lower-inequality regions. This contrasts with the evidence of higher inequality in income in large cities and global cities.

However, the results are very sensitive to the exact measure used. For example, using the 50:10 ratio, housing space inequality increased in nine rather than ten regions (the South West was the exception). More radically, using the 90:50 ratio it increased in only one region. This indicates that the choice of definition and measure of inclusive housing growth, and indeed probably of inclusive growth of all kinds, is extremely important to our results. It also suggests that for housing space, the situation of those at the 10th percentile was a key driver of changes in housing space inequality at regional level.

\subsection{Local Authorities}

In terms of change for the worst-off, in 254 (or $73 \%$ of all the 348 local authorities in England and Wales), those at the worst-housed 10th percentile made some absolute gain in housing space per person 1981-2011. However, in most cases absolute gains were very small, averaging a perhaps-imperceptible $0.2 \mathrm{r} / \mathrm{p}$ over thirty years. The most the worst-housed gained was $0.5 \mathrm{r} / \mathrm{p}$, in Cotswold, a rural area in the South East with high overall growth.

In 88 (or $25 \%$ of the total), those in the worst-housed decile made no gains in space per person. These areas included London boroughs, other smaller towns in the South East and East of England, and large cities and smaller towns in the north and Wales, including Newcastle and Cardiff. In six (2\%), all London boroughs, the absolute position of the worst-housed actually deteriorated. For example, in Greenwich, in 1981 those at the 10th percentile had $1.0 \mathrm{r} / \mathrm{p}$, but by 2011 they had only $0.8 \mathrm{r} / \mathrm{p}$.
Regarding inequality, the vast majority of local authorities (84\%) had a 90:10 ratio of 3.0 in 1981, although there was a range from 2.5 to 3.8 . Over 1981-2011, housing space inequality increased in 325 (or 93\%) of the total. However, the median increase in the $90: 10$ ratio was relatively modest at $11 \%$.

Again, the results are very sensitive to the exact measure used. Using the 50:10 ratio, inequality in housing space increased in only 218 (63\%) of local authorities. Using the 90:50 ratio, it increased in a bare majority, 182 (52\%). Again, this indicates that the choice of definition and measure of inclusive housing growth is extremely important to the outcome, and that the situation of the worst-off was a key driver of changes in inequality at local as well as at national and regional level.

\subsection{Summary}

There are eight possible combinations of 'housing growth,' 'inclusivity' and 'justice.' Table 1 summarises evidence to categorise change in England and Wales, its regions and local authorities 1981-2011 (Table 1).

In summary, over 1981-2011, England and Wales as a whole achieved housing growth but it was not inclusive or just. Six of the ten regions managed to achieve inclusive housing growth. None achieved just growth, and London did not achieve growth of any kind.

242 local authorities (or $70 \%$ of the total 348 in England and Wales), achieved inclusive but not just growth. In these areas, the worst-off made gains, but they were very modest ones. Meanwhile, better-housed people made more significant absolute and relative gains, so inequality increased. The next largest group of local authorities, 76 (or 22\%), achieved growth but it was neither inclusive nor just, so in these areas the worst- 
Table 1. Housing growth, inclusivity and justice at national, regional and local authority level, 1981-2011.

Inclusivity (Change in Position of Worst-Off and in Housing Space Inequality)

No absolute gain for worst-off, and increase in inequality
Housing Growth (Median Space per Person)

$\begin{array}{ll}\text { No Growth } & \text { Growth } \\ \text { Non-inclusive and non-just } & \text { Non-inclusive and non-just } \\ \text { non-growth } & \text { growth } \\ 1 / 10 \text { regions } & \text { England and Wales } \\ 2 \% \text { local authorities } & 3 / 10 \text { regions } \\ & 22 \% \text { local authorities }\end{array}$

Inclusive but non-just non-growth (no cases)

Inclusive but non-just growth $6 / 10$ regions

$70 \%$ local authorities

No absolute gain for worst-off, but no increase in inequality

Non-inclusive but just non-growth $1 \%$ local authorities

Non-inclusive but just growth $2 \%$ local authorities

Inclusive, just non-growth $<1 \%$ local authorities
Inclusive, just growth

$3 \%$ local authorities
Absolute gain for worst-off
no increase in inequality off gained nothing, while others gained so there was an increase in inequality. Just nine local authorities (3\%) achieved inclusive, just, growth.

In the 15 local authorities where there was no growth, higher proportions (7/15) achieved 'just' outcomes than in the much more numerous examples with growth. However, in these cases, justice was only achieved alongside no gain either for the worst-off or for the median.

\section{Characteristics of the Local Authorities that Achieved Inclusive or Just Growth}

As noted above, we might expect to find inclusive and just growth in areas with growth in mean rooms per person, median rooms per person, or low or falling populations. Other factors such as regional location, population size, urbanity and deprivation might play a role.

The 242 inclusive but non-just growth areas were varied. The majority were in the 6 inclusive but non-just regions. They were mostly medium-sized and smaller cities and towns, compared to non-inclusive and nonjust growth areas which included more in major conurbations (Department for Environment, Food and Rural Affairs [DEFRA], 2011). The inclusive but non-just growth areas were typically slightly less deprived than the comparators (MHCLG, 2019), so deprivation might be some barrier to inclusivity. Population growth in these areas was very similar to that in comparators areas. Housing growth averaged $0.4 \mathrm{r} / \mathrm{p}$, compared to $0.3 \mathrm{r} / \mathrm{p}$ in other areas (averages not weighted for population).

The very small group of nine inclusive and just growth local authorities were very varied, and difficult to characterise. They included Hammersmith and Fulham, Islington and Wandsworth in London, Birmingham and Sandwell in the West Midlands conurbation, and four smaller, more rural authorities scattered round England: Rother, Ryedale, South Lakeland and North Norfolk
(DEFRA, 2011). Regional location did not seem to be a significant factor in the distribution, as seven of the nine were in non-inclusive, non-just regions. The inclusive and just areas included some of the most deprived local authorities in England and some more advantaged ones (MHCLG, 2019). Population growth in these areas was again close to the overall average. Housing growth averaged $0.3 \mathrm{r} / \mathrm{p}$ or $19 \%$, very similar to that in non-inclusive non-just local authorities.

This small group of local authorities may not provide transferable models for many other areas in the UK or further afield. Firstly, the reductions in the 90:10 ratio they achieved were small, ranging from $1 \%$ to $8 \%$. Secondly, all residents in the 5 areas in the London and West Midlands areas were poorly housed relative to national standards, those at the 10th percentile had just $0.8 \mathrm{r} / \mathrm{p}$ in 1981, and those at the 90th percentile had 2.5 or $3.0 \mathrm{r} / \mathrm{p}$. Thirdly, the other cases were rural and low population areas very different from places where most people live.

Looking across all local authorities, there was no evidence to support the idea that low or falling population might allow room for more inclusive distribution as, across all local authorities, there was very little relationship between population growth and the position of the worst-off or of inequality. There was a correlation between greater housing growth and greater gains for the worst-off. In contrast, greater housing growth was associated with greater increases in inequality, as those at the 90th percentile tended to gain more in absolute and relative terms from growth. Thus, low housing growth was associated with more just outcomes. This provides support for the idea that there might be policy choices between increasing housing supply and reducing housing inequalities (Robinson et al., 1985). It also underlines the point that results are sensitive to definitions and measures. Across all local authorities, there was small correlation between lower area deprivation and greater inclusiv- 
ity and justness, which suggests deprivation may create some barrier to more inclusive housing growth.

\section{Conclusion}

There is global concern from governments and organisations about who gains from growth, and in how to make growth more 'inclusive' or 'just.' In housing development, concerns about the scale of housing supply are accompanied by concerns about how new supply is distributed. This article has reported evidence on the growth and distribution of housing space over the long-term, in a highincome country with high income inequality but relative low housing inequality.

The concept of 'inclusive growth' can be applied to housing. Housing is an important area of consumption and source of inequality, but one in which simple categorical measures of inequality have so far predominated.

The article has developed and applied new definitions and measures. 'Housing growth' is growth in median housing space per person. 'Inclusive growth' occurs where the worst-off gain from growth. The more demanding 'just growth' occurs without an increase in housing space inequality. A new set of continuous data for England and Wales was developed and applied to show that these concepts can be measured empirically, over time and at national and local level. This could be extended, where data permit, to the many nations that collect data on housing floorspace and other continuous variables.

Over 1981-2011, while England and Wales as a whole achieved 'housing growth' in median space per person, four of ten regions including London failed to so, as did $3 \%$ of local authorities.

Housing growth can be achieved in a variety of places, and with different combinations of population and housing growth. However, a small negative correlation between local authority rates of housing growth and population growth suggests it is more difficult to maintain housing growth where the population is growing fast.

Results are sensitive to definitions and measures. This means empirical claims about 'inclusive growth' should be examined closely for details of the definitions and data used. The concept of 'inclusivity' applied here is relatively undemanding, and 'just growth' was much more elusive than 'inclusive' growth. Researchers and policymakers may want to specify that growth is only 'inclusive' if the worst-off make more than trivial gains or might want to aspire to 'just' growth instead. In addition, measuring inequality with different ratios produces very different results. The definitions and measures presented here could be adapted to specific national or local issues, but care is needed in applying measures.

As with inclusive economic growth, inclusive and just housing growth can be achieved. Over 1981-2011, while England and Wales as a whole achieved housing growth in space per person it was not inclusive or just. Six of the ten regions managed to achieve inclusive hous- ing growth, but none achieved just growth. $70 \%$ of local authorities achieved 'inclusive' but not 'just' growth. In these areas, the worst-off made very modest gains over the thirty years. Meanwhile, better-housed people made more significant absolute and relative gains. At national level, in every region and in $93 \%$ of local authorities, inequality increased. Like the nation, $22 \%$ of local authorities had growth that was neither 'inclusive' nor just. Almost without exception, those who gained most from new housing development in England and Wales 1981-2011 were those who were already better housed.

Just $3 \%$ of local authorities achieved growth that was both inclusive and just. This small group may not provide transferable models for many other areas in the UK or further afield. They achieved only small reductions in inequality and were either poorly-housed relative to national standards or were atypical as rural and low population areas.

Looking across all local authorities there was no evidence to support the idea that low or falling population encourages more inclusive or just distribution of housing space.

Greater housing growth (in median space per person) appeared to be associated with greater gains for the worst-off. However, greater housing growth was associated with increases in inequality. Deprivation may create some barriers to more inclusive housing growth.

There were a few local areas where 'non-growth' in median space per person, potentially a preferred outcome for those focussed on sustainability, was inclusive and just. This reflects the national experience in decades before 1981 and parallels some cases of economic stagnation in the UK and elsewhere.

The rarity of significant improvements for the worstoff and the ubiquity of increasing inequality at national, regional and local level in England and Wales, suggests considerable scope for improving the inclusivity of housing supply, as a complement or even potential alternative to increased quantity. It should be noted that Inclusive and just housing growth have been achieved at national level in England and Wales in several twentieth century decades. However, results also suggest that, at least in the UK, local initiatives may be insufficient to create change today, and more substantial and systematic national level changes may be required. In addition, while housing growth and inclusivity can co-exist, there may be a policy choice between more housing growth and reduced inequality.

There is potential for further research to explain variations seen across time and space in England and Wales, and for comparative research, where data permit, in nations with different housing systems and different levels of income inequality to that in the UK.

\section{Acknowledgments}

Thanks to seminars at the Housing Studies Association, the University of Cambridge, and University College 
London for comments on presentations based on early analyses of the data presented.

\section{Conflict of Interests}

The author declares no conflict of interests.

\section{References}

Arundel, R. (2017). Equity inequity: Housing wealth inequality, inter- and intra-generational divergences, and the rise of private landlordism. Housing, Theory and Society, 34(2), 176-200.

Atkinson, A. B. (1970). On the measurement of inequality. Journal of Economic Theory, 2(3), 244-263.

Benner, C., \& Pastor, M. (Eds.). (2012). Just growth: Inclusion and prosperity in America's metropolitan regions. Abingdon: Routledge.

Bleys, B. (2012). Beyond GDP: Classifying alternative measures for progress. Social Indicators Research, 109, 355-376.

Bradshaw, J., Chzhen, Y., \& Stephens, M. (2008). Housing: The saving grace in the British welfare state? In S. Fitzpatrick \& M. Stephens (Eds.), The future of social housing (pp. 7-25). London: Shelter.

Carr, H. (2016). Room to live? Socio-legal reflections on the United Kingdom's politics of housing space. In N. Davidson \& N. Mistry (Eds.), Law between buildings: Emergent global perspectives in urban law. London: Routledge.

CECODHAS. (2019). The state of housing in Europe 2019. Brussels: CECODHAS.

Chapple, K. (2018) .Just growth: Strategies for growth with equity. In G. L. Clark, M. P. Feldman, M. S. Gertler, \& D. Wójcik (Eds.), The new Oxford handbook of economic geography (pp. 792-809). Oxford: Oxford University Press.

Cole, I., Crisp, R., Eadson, W., Ferrari, E., Powell, R., \& While, A. (2017). Tackling poverty through housing and planning policy in city regions. York: JRF.

Commission on Growth and Development. (2008). Growth report: Strategies for sustained growth and inclusive development. Washington, D.C.: The World Bank.

Conservative Party. (2019). Get Brexit done, unleash Britain's potential: The Conservative and Unionist Party manifesto. London: Conservative Party.

Council of European Development Bank. (2017). Housing inequality in Europe: Tackling inequalities in Europe. The role of social investment. Paris: CEB.

de Wilde, C., \& de Decker, P. (2016). Changing inequalities in housing outcomes across Western Europe. Housing, Theory and Society, 33(2), 121-161.

Department for Communities and Local Government. (2017). Fixing our broken housing market. London: DCLG.

Department for Environment, Food and Rural Affairs. (2011). 2011 rural-urban classification of local authorities and other geographies. London: DEFRA.
Dorling, D. (2014). All that is solid: The great housing disaster. London: Allen Lane.

Dorling, D., Ford, J. M., Holmans, A., Sharp, C., Thomas, B., \& Wilcox, S. (2005). The great divide: An analysis of housing inequality. London: Shelter.

European Commission. (2010). Europe 2020: A strategy for smart, sustainable and inclusive growth. Brussels: European Commission.

Eurostat. (2020). EU-SILC Tables TESSI172, LVHO04, PEPS07. Retrieved from https://ec.europe/eurostat

Feng, W. (2008). Boundaries and categories: Rising inequalities in post-socialist urban China. Stanford, CA: Stanford University Press.

Fitzpatrick, S., Pawson, H., Bramley, G., Wilcox, S., Watts, B., \& Wood, J. (2019). The homelessness monitor: England 2019. London: Crisis.

General Register Office. (1904). Census of England and Wales 1901: General report with appendices. London: HMSO.

Gibbons, S., Sanchez-Vidal, M., \& Silva, O. (2018). The bedroom tax. Regional Science and Urban Economics, 82. https://doi.org/10.1016/j.regsciurbeco.2018.12. 002

Goodchild, B., \& Furbey, C. (1986). Standards in housing design: A review of the main changes since the Parker Morris report (1961). Land Development Studies, 3(2), 77-99.

Hall, I. (2011). The Coalition and the UK housing market. Politics, 31, 72-81.

Hills, J., Brewer, M., Jenkins, S., Lister, R., Lupton, R., Machin, S., . . . Riddell, S. (2010). An anatomy of economic inequality in the UK: The report of the $\mathrm{Na}$ tional Equality Panel. London: Government Equalities Office.

lanchovichina, E., \& Lundstrom, S. (2009). Inclusive growth analytics: Framework and application (Policy Research Working Paper 4851). Washington, DC: World Bank.

Inclusive Growth Commission. (2017). Inclusive growth commission: Making our economy work for everyone. London: RSA.

Kohil, A., Moon, C.-I., \& Sorensen, G. (2003). States, markets, and just growth: Development in the twentyfirst century. Tokyo: United Nations University Press.

Landis, J. D., Elmer, V., \& Zook, M. (2002). New economy housing markets: Fast and furious-But different? Housing Policy Debate, 13(2), 233-274.

Lee, N. (2019). Inclusive growth in cities: A sympathetic critique. Regional Studies, 53(3), 424-434.

Lupton, R., Tunstall, R., Sigle-Rushton, W., Obolenskaya, P., Sabates, R., Meschi, E., ... Salter, M. (2009). Growing up in social housing in Great Britain: The experience of four generations. London: Tenant Services Authority, JRF and the Scottish Government.

Lupton, R., Burchardt, T., Hills, J., Stewart, K., \& Vizard, P. (2016) Social policy in a cold climate: Policies and their consequences since the crisis. Bristol: Policy Press. 
Marmot Review Team. (2010). Fair society, healthy lives. London: Strategic Review of Health Inequalities in England Post-2010.

Marsh, A. D., Gordon, D., Heslop, P., \& Pantazis, C. (2000). Housing deprivation and health: A longitudinal analysis. Housing Studies, 15(3), 411-428.

Ministry of Housing Communities and Local Government. (2018). English housing survey: Floorspace in English homes. Main report. London: MHCLG.

Ministry of Housing Communities and Local Government. (2019). Index of multiple deprivation 2019. London: MHCLG. Retrieved from https://www. gov.uk/government/statistics/english-indices-ofdeprivation-2019

Murie, A. (1983). Housing inequality and deprivation. London: Heinemann.

OECD. (2008). Growing unequal? Income distribution and poverty in OECD countries. Paris: OECD.

OECD. (2018). Opportunities for all: A framework for policy action on inclusive growth. Paris: OECD.

ONS. (2019). Household income inequality, UK: Financial year ending 2019 (provisional). London: ONS.

Phang, S. Y. (2019). Building an equitable and inclusive city through housing policies: Singapore's experience. In R. L. H. Chiu, Z. Liu, \& B. Renaud (Eds.), International housing market experience and implications for China. London: Routledge.

Piketty, T. (2014). Capital in the twenty-first century. Cambridge, MA: Harvard University Press.
Robinson, R., O'Sullivan, T., \& Le Grand, J. (1985). Inequality and housing. Urban Studies, 22(3), 249-256.

Scanlon, K., Arrigoitia Fernandez, M., \& Whitehead, C. (2015). Social housing in Europe. European Policy Analysis, 2015(17), 1-12.

Stephens, M., Perry, J., Wilcox, S., Williams, P., \& Young, G. (2019). UK housing review 2019. Coventry: Chartered Institute of Housing.

Tan, S., Wang, S., \& Chen, C. (2016). Change of housing inequality in urban China and its decomposition: 1989-2011. Social Indicators Research, 129, 29-45.

Trust for London. (2017). London's poverty profile. London: Trust for London.

Tunstall, B. (2015). Relative housing space inequality in England and Wales and its recent rapid resurgence. International Journal of Housing Policy, 15(2), 105-126.

Vandemoortele, M., Bird, K., Du Toit, A., Liu, M., Sen, K., \& Veras Soares, F. (2013). Building blocks for equitable growth: lessons from the BRICS (Working Paper No. 365). London: Overseas Development Institute.

Whitehead, C., \& Williams, P. (2011). Causes and consequences? Exploring the shape and direction of the housing system in the UK post the financial crisis. Housing Studies, 26(7/8), 1157-1169.

Wilson, W., \& Barton, C. (2019). Statutory homelessness in England (House of Commons Library Briefing Paper No. 01164). London: House of Commons Library.

\section{About the Author}

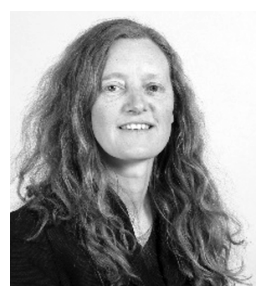

Rebecca Tunstall is Professor Emerita of Housing at the University of York, UK. She was previously Director of the Centre for Housing Policy at York, and Course Director of the MSc/Diploma in Housing at the London School of Economics. She specialises in social housing, neighbourhoods and inequality. 